Revista Nacional de

\title{
Concreto com incorporação de resíduo de PET
}

Concrete with incorporation of PET residue

Hormigón con incorporación de residuo de PET

Lucas Henrique Lozano Dourado de Matos

Aluno de Mestrado, UNESP Ilha Solteira, Brasil. englhmatos@gmail.com

Leticia Martelo Pagoto

Aluna de Mestrado, UNESP Ilha Solteira, Brasil. leppagoto@yahoo.com.br

Mariana Barbosa de Carvalho Aluna de Mestrado, UNESP Ilha Solteira, Brasil. maa.carvalho@hotmail.com 


\section{RESUMO}

À medida que a população e seu poder de compra crescem, aumentam também as discussões acerca dos impactos ambientais oriundos dos resíduos produzidos. Apesar do empenho existente em reduzir a produção de resíduos, é impossível eliminá-los totalmente, de forma que a reciclagem ou reutilização é uma alternativa ao problema, especialmente no setor da construção civil. Uma grande questão atualmente é quanto aos resíduos gerados pela resina de $\mathrm{PET}$, já que boa parte deste material não encontra destinação adequada, e além de ser um resíduo não biodegradável, sua queima em incineradores domésticos gera substâncias nocivas ao meio ambiente. Assim, buscando uma alternativa aos problemas mencionados, foi realizado um estudo produzindo concreto com substituição parcial do agregado miúdo por resíduo de PET na proporção de $30 \%$ para diferentes teores de argamassa. Para tanto, foi realizada a dosagem dos traços de referência padrão (1:5), rico $(1: 3,5)$ e pobre $(1: 6,5)$. Em seguida foi realizada a dosagem dos traços com PET, utilizando a mesma metodologia, o mesmo teor de argamassa, e substituindo a areia pelo resíduo de PET em volume. Para cada traço foi realizado o ensaio de abatimento do tronco de cone e foram realizados ensaios de resistência à compressão axial aos 7 dias de idade. $O$ estudo mostrou que, apesar da queda na resistência à compressão para todos os traços do concreto com adição de resíduo de PET, o traço rico se mostrou o mais viável para aplicação estrutural, enquanto o concreto produzido com outros traços pode ser utilizado para fins não estruturais.

PALAVRAS-CHAVE: Resíduo. Concreto. Pet.

\section{ABSTRACT}

As the population and its purchasing power grow, so does the discussion about the environmental impacts of the produced waste. Despite the commitment to reduce waste production, it is impossible to dispose of them completely, so recycling or reuse is an alternative to the problem, especially in the construction sector. A major issue today is the waste generated by the PET resin, since much of this material does not have adequate disposal, and besides being a non-biodegradable waste, its burning in domestic incinerators generates substances that are harmful to the environment. Thus, searching for an alternative to the mentioned problems, a study was carried out producing concrete with partial replacement of the fine aggregate by PET residue in the proportion of $30 \%$ for different mortar contents. For this purpose, the standard $(1: 5)$, rich $(1: 3,5)$ and poor $(1: 6,5)$ reference traces were measured. Afterwards, the PET traces were measured using the same methodology, the same mortar content, and replacing the sand with the PET residue in volume. For each trace it was performed the slump test and the axial compression resistance tests at 7 days of age. The study showed that, despite the decrease in compressive strength for all traces of concrete with addition of PET residue, the rich trace was the most feasible for structural application, while the concrete produced with other traces could be used for non-structural purposes.

KEY WORDS: Residue. Concrete. Pet.

\section{RESUMEN}

A medida que crece la población y su poder adquisitivo, también lo hace la discusión sobre los impactos ambientales de los desechos producidos. A pesar del empeño en reducir la producción de residuos, es imposible eliminarlos por completo, por lo que el reciclaje o la reutilización es una alternativa al problema, especialmente en el sector de la construcción. Un problema importante en la actualidad es el residuo generado por la resina de PET, ya que gran parte de este material no cuenta con una eliminación adecuada, y además de ser un residuo no biodegradable, su incineración en incineradores domésticos genera sustancias nocivas para el medio ambiente. Así, buscando una alternativa a los problemas mencionados, se realizó un estudio de producción de concreto con reemplazo parcial del agregado fino por residuos de PET en la proporción de $30 \%$ para diferentes contenidos de mortero. Para eso, se midieron los rastros de referencia estándar (1:5), rico $(1: 3,5)$ y pobre $(1: 6,5)$. Posteriormente, las trazas de PET se midieron utilizando la misma metodología, el mismo contenido de mortero y reemplazando la arena con el residuo de PET en volumen. Para cada traza se realizó la prueba de asentamiento y las pruebas de resistencia a la compresión axial a los 7 días de edad. El estudio demostró que, a pesar de la disminución en la resistencia a la compresión de todos los rastros de hormigón con adición de residuos de PET, el rastro rico era el más factible para la aplicación estructural, mientras que el concreto producido con otros rastros podía usarse para fines no estructurales.

PALABRAS CLAVE: Residuo. Hormigón. Pet. 


\section{INTRODUÇÃO}

O aumento da população e seu poder de compra mudaram a geração de resíduos. Os resíduos produzidos atualmente são diferentes em volume e qualidade dos resíduos produzidos em épocas passadas. A industrialização trouxe, naturalmente, mais materiais descartáveis e como consequência desse acréscimo, mais materiais são encontrados nos aterros sanitários.

Paralelamente ao desenvolvimento socioeconômico, as discussões dos impactos ambientais oriundos dos resíduos é uma mostra do quão necessário é a inclusão destes aspectos para o desenvolvimento ordenado. A questão ambiental é discutida há anos, no âmbito nacional e internacional, mobilizando a opinião pública e tornando-se um importante fator cotidiano.

A indústria da construção civil é responsável pelo maior impacto ambiental negativo, devido ao alto consumo de matéria-prima. Conforme Agopyan (2013), a construção civil consome de $40 \%$ a $75 \%$ da matéria-prima mundial.

De acordo com a ANEPAC (2015), a construção civil nacional consome, para a produção de concreto e argamassa, em torno de 500 milhões de toneladas de agregados, onde aproximadamente $60 \%$ deste consumo é de areia. Por outro lado, as indústrias relacionadas à construção civil geram um elevado número de poluentes ambientais.

Em virtude disso, reduzir a produção de resíduos é um objetivo a ser alcançado. No entanto, apesar do empenho considerável das indústrias, é impossível eliminar totalmente a geração de resíduos em diversos processos. Agopyan e John (2011), estimam que 50\% a 75\% dos materiais retirados da natureza retornem como resíduos dentro do período de um ano.

A reciclagem ou reutilização é uma alternativa ao problema de geração de resíduos, propiciando economia de energia e conservação de recursos naturais. Principalmente quando esta alternativa é aplicada na construção civil, setor da indústria que mais consome recursos naturais e um dos maiores poluentes globais.

O Brasil produziu, em 2015, cerca de 537 mil toneladas de resina de pet. E apesar do alto índice de reciclagem, de $51 \%$, os $49 \%$ restantes, que foram para o lixo, são suficientes para preencherem aproximadamente 40 mil caminhões. Mas boa parte deste material não encontra sua destinação adequada e acaba parando nas calçadas e bueiros, provocando enchentes e propiciando o desenvolvimento de agentes transmissores de doenças, beira de estradas, rios e, por fim, nos mares e oceanos, onde estima-se que até 2050 este resíduo ultrapasse a quantidade de peixes nas águas (ABIPET, 2016).

Definindo-se os resíduos de PET como sólidos indesejáveis, uma vez que sua decomposição é muito lenta, podendo desencadear efeitos nocivos e adversos se utilizados em incineradores de resíduos domésticos, além de seu acúmulo e descarte incorreto apresentar riscos ambientais. Sua decomposição é de ordem indeterminada, podendo se estender por centenas de anos na natureza, por ser um resíduo não biodegradável, e sua queima em incineradores de resíduos domésticos gera substâncias nocivas ao meio ambiente e à saúde de humanos e 
animais, podendo agravar o surgimento de doenças neurológicas, cardiovasculares e cânceres (VERMA et al., 2016).

\section{OBJETIVO}

Este trabalho tem como objetivo buscar uma alternativa sustentável à um passivo ambiental, o resíduo de $\mathrm{PET}$, produzindo concreto com substituição parcial do agregado miúdo por resíduo de PET na proporção de 30\% para os teores de argamassa de 1:3,5, 1:5 e 1:6,5 analisando as propriedades de trabalhabilidade e resistência à compressão axial.

\section{METODOLOGIA}

\subsection{MATERIAIS}

\subsubsection{CIMENTO}

O cimento utilizado na pesquisa foi o cimento Portland CPII Z-32 da marca Ciplan.

\subsubsection{AGREGADO MIÚDO}

O agregado miúdo utilizado foi areia natural lavada.

\subsubsection{AGREGADO GRAÚDO}

Utilizou-se agregado graúdo natural basáltico.

\subsection{4 ÁGUA DE AMASSAMENTO}

A água de amassamento utilizada foi oriunda da rede pública e fornecida pela Prefeitura Municipal de Ilha Solteira - SP.

\subsubsection{PET}

O PET utilizado foi fornecido em formato de flakes pela empresa Global PET SA, localizada na cidade de São Carlos, SP (Figura 1). 


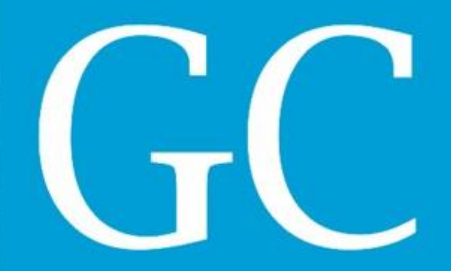

Revista Nacional de

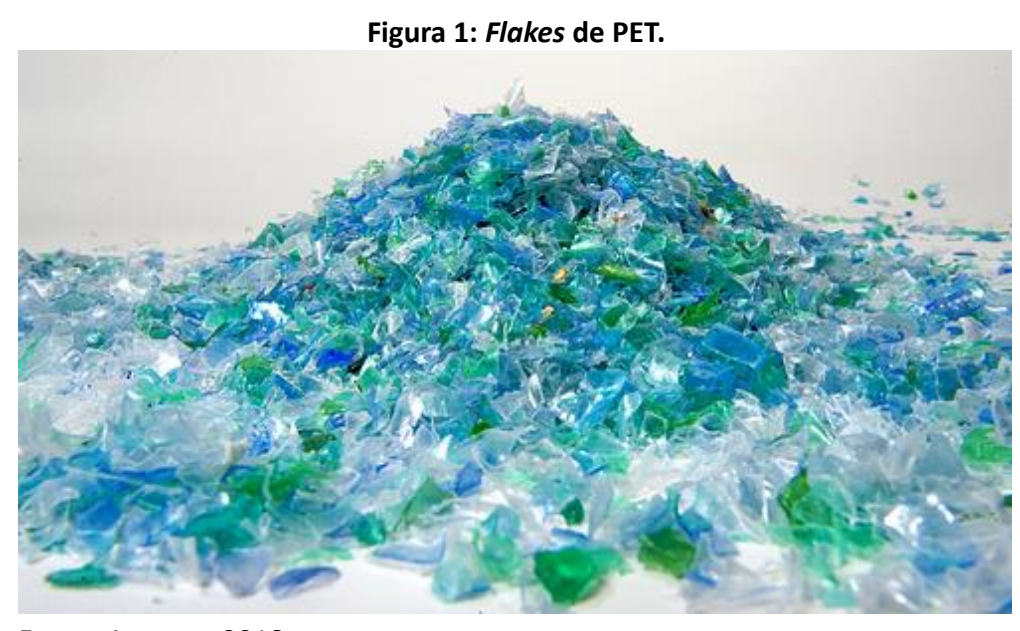

Fonte: Autores, 2018.

\subsection{MÉTODOS}

\subsubsection{CARACTERIZAÇÃO DOS MATERIAIS}

\subsubsection{CIMENTO}

A caracterização do cimento foi realizada segundo a NBR 11578 (ABNT, 1991 - versão corrigida 1997) e os resultados dos ensaios, fornecidos pelo fabricante, estão apresentados na Tabela 1.

Tabela 1: Resultados dos índices físicos do cimento Portland utilizado.

\begin{tabular}{|c|c|c|c|c|c|c|c|c|}
\hline $\begin{array}{l}\text { Blaine } \\
\text { (cm/g) }\end{array}$ & $\begin{array}{c}\text { Massa } \\
\text { específica } \\
\text { absoluta } \\
\left(\mathrm{g} / \mathrm{cm}^{3}\right)\end{array}$ & $\begin{array}{c}\text { Massa } \\
\text { unitária } \\
\left(\mathrm{g} / \mathrm{cm}^{3}\right)\end{array}$ & $\begin{array}{c}\text { Tempo } \\
\text { de pega } \\
\text { inicial } \\
\text { (min) }\end{array}$ & $\begin{array}{c}\text { Tempo } \\
\text { de pega } \\
\text { final } \\
\text { (min) }\end{array}$ & $\begin{array}{c}\text { Resistência } \\
\text { à } \\
\text { compressão } \\
1 \text { dia }\end{array}$ & $\begin{array}{c}\text { Resistência } \\
\text { à } \\
\text { compressão } \\
3 \text { dias }\end{array}$ & $\begin{array}{c}\text { Resistência } \\
\text { à } \\
\text { compressão } \\
7 \text { dias }\end{array}$ & $\begin{array}{c}\text { Resistência } \\
\text { à } \\
\text { compressão } \\
28 \text { dias }\end{array}$ \\
\hline 5000 & 3,00 & 0,95 & 195 & 270 & 15,0 & 23,0 & 28,0 & 33,0 \\
\hline
\end{tabular}

Fonte: Elaborado pelos autores.

\subsubsection{CARACTERIZAÇÃO DO AGREGADO MIÚDO}

A composição granulométrica do agregado miúdo foi obtida conforme prescrito na norma NBR NM 248 (ABNT, 2003). A composição granulométrica pode ser visualizada na Tabela 2, com a curva granulométrica correspondente apresentada na Figura 2. 


\section{Revista Nacional de}

Tabela 2: Composição granulométrica do agregado miúdo.

\begin{tabular}{cccc}
\hline $\begin{array}{c}\varnothing \text { Peneira } \\
(\mathbf{m m})\end{array}$ & $\begin{array}{c}\text { Massa retida } \\
\mathbf{( g )}\end{array}$ & $\begin{array}{c}\text { \% Retida em } \\
\text { cada peneira }\end{array}$ & $\begin{array}{c}\text { \% Retida } \\
\text { acumulada }\end{array}$ \\
\hline 6,3 & 0,0 & 0,00 & 0,00 \\
4,75 & 2,0 & 0,17 & 0,17 \\
2,36 & 3,4 & 0,28 & 0,45 \\
1,18 & 15,2 & 1,27 & 1,72 \\
0,6 & 135,8 & 11,34 & 13,06 \\
0,3 & 523,3 & 43,87 & 56,94 \\
0,15 & 492,1 & 41,10 & 98,04 \\
0,075 & 23,5 & 1,96 & 100,00 \\
\hline Total & $\mathbf{1 1 9 7 , 3}$ & $\mathbf{1 0 0 , 0 0}$ & $\mathbf{2 7 0 , 3 8}$ \\
\hline
\end{tabular}

Fonte: Elaborado pelos autores.

Figura 2: Curva granulométrica do agregado miúdo.

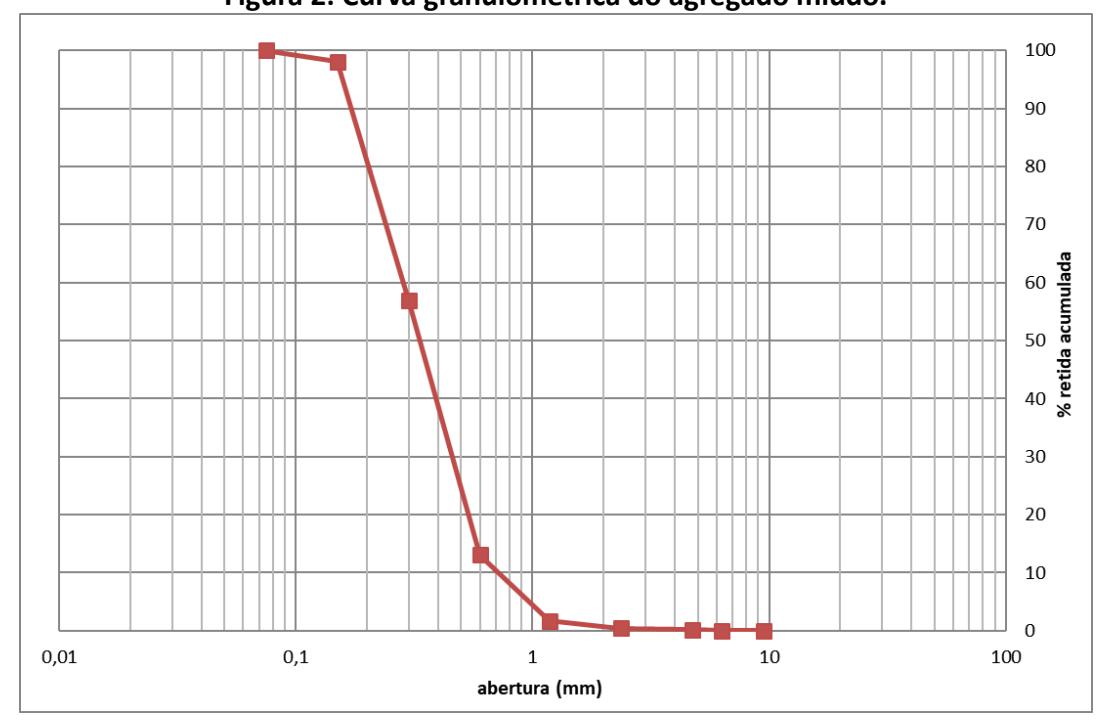

Fonte: Autores, 2018.

A determinação da massa específica dos materiais é importante para a elaboração de dosagens e traços do concreto, pois conhecendo o seu resultado é possível calcular o consumo de materiais utilizados para a produção das misturas. A massa específica do material pode ser definida como a massa do material por unidade de volume excluindo-se os poros permeáveis, e na massa unitária inclui-se os poros permeáveis.

Para a determinação da massa unitária e massa específica seguiram-se as prescrições da NBR NM 52 (ABNT, 2009).

Na Tabela 3 são apresentados os índices de caracterização para o agregado miúdo utilizado. 
Tabela 3: Resultados da caracterização do agregado miúdo.

\begin{tabular}{cccccc}
\hline $\begin{array}{c}\text { Diâmetro } \\
\text { máximo } \\
(\mathbf{m m})\end{array}$ & $\begin{array}{c}\text { Módulo } \\
\text { de } \\
\text { finura }\end{array}$ & $\begin{array}{c}\text { Massa } \\
\text { específica } \\
\text { absoluta } \\
\left(\mathrm{g} / \mathrm{cm}^{3}\right)\end{array}$ & $\begin{array}{c}\text { Massa } \\
\text { unitária } \\
\left(\mathrm{g} / \mathrm{cm}^{3}\right)\end{array}$ & $\begin{array}{c}\text { Absorção } \\
(\%)\end{array}$ & $\begin{array}{c}\text { Pulverulento } \\
(\%)\end{array}$ \\
\hline 1,18 & 2,70 & 2,61 & 1,64 & 0,34 & 0,48 \\
\hline Fonte: Elaborado pelos autores.
\end{tabular}

Fonte: Elaborado pelos autores.

O diâmetro máximo característico do agregado miúdo é de $1,18 \mathrm{~mm}$ e o Módulo de Finura é igual 2,70, o que caracteriza o material como sendo areia média, de acordo com a NBR 7214 (ABNT, 2015), como mostra a Tabela 4.

Tabela 4: Classificação dos agregados miúdos segundo a NBR 7214.

\begin{tabular}{cc}
\hline Intervalos do Módulo de Finura & Classificação do agregado miúdo \\
\hline $2,90<\mathrm{MF}<3,50$ & Grossa \\
$2,20<\mathrm{MF}<2,90$ & Média \\
$1,55<\mathrm{MF}<2,20$ & Fina \\
\hline Fonte: NBR 7214, (ABNT, 2015)
\end{tabular}

\subsubsection{CARACTERIZAÇÃO DO AGREGADO GRAÚDO}

Os agregados cujos grãos ficam retidos, em sua maior parte, na peneira com abertura de 4,75 mm são classificados como agregado graúdo.

A composição granulométrica do agregado graúdo foi obtida conforme prescrito na norma NBR NM 248 (ABNT, 2003). A composição granulométrica do agregado graúdo pode ser visualizada na Tabela 5, com a curva granulométrica correspondente apresentada na Figura 3.

Tabela 5: Composição granulométrica do agregado graúdo.

\begin{tabular}{cccc}
\hline $\begin{array}{c}\varnothing \text { Peneira } \\
(\mathbf{m m})\end{array}$ & $\begin{array}{c}\text { Massa retida } \\
(\mathbf{g})\end{array}$ & $\begin{array}{c}\text { \% Retida em } \\
\text { cada peneira }\end{array}$ & $\begin{array}{c}\text { \% Retida } \\
\text { acumulada }\end{array}$ \\
\hline 25 & 0 & 0,00 & 0,00 \\
19 & 0 & 0,00 & 0,00 \\
12,5 & 2110 & 34,40 & 34,40 \\
9,5 & 2700 & 44,00 & 78,39 \\
6,3 & 1146 & 18,68 & 96,49 \\
4,75 & 75 & 1,22 & 97,07 \\
2,36 & 105 & 1,71 & 98,29 \\
1,18 & 0 & 0,00 & 100,00 \\
\hline Total & $\mathbf{6 1 3 6}$ & $\mathbf{1 0 0 , 0 0}$ & $\mathbf{5 0 8 , 1 3}$ \\
\hline
\end{tabular}

Fonte: Elaborado pelos autores. 


\section{Revista Nacional de}

Figura 3: Curva granulométrica do agregado graúdo.

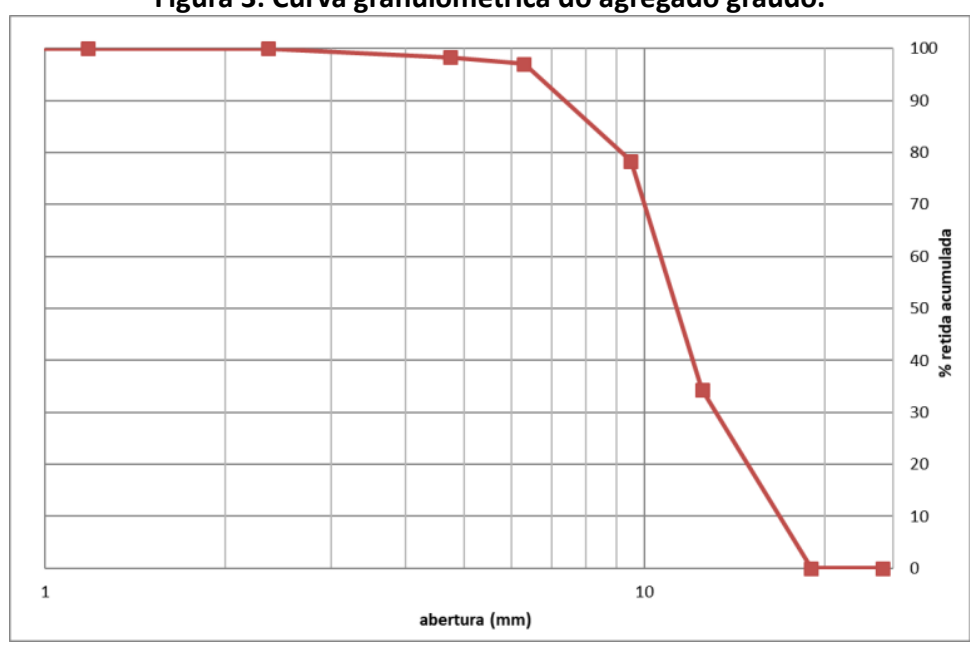

Fonte: Autores, 2018.

Para a determinação da massa unitária e massa específica seguiram-se as prescrições da NBR NM 53 (ABNT, 2009).

Na Tabela 6 são apresentados os índices de caracterização para o agregado graúdo utilizado.

Tabela 6: Resultados da caracterização do agregado graúdo.

\begin{tabular}{cccccc}
\hline $\begin{array}{c}\text { Diâmetro } \\
\text { máximo } \\
(\mathrm{mm})\end{array}$ & $\begin{array}{c}\text { Módulo } \\
\text { de } \\
\text { finura }\end{array}$ & $\begin{array}{c}\text { Massa } \\
\text { específica } \\
\text { absoluta } \\
\left(\mathrm{g} / \mathrm{cm}^{3}\right)\end{array}$ & $\begin{array}{c}\text { Massa } \\
\text { unitária } \\
\left(\mathrm{g} / \mathrm{cm}^{3}\right)\end{array}$ & $\begin{array}{c}\text { Absorção } \\
(\%)\end{array}$ & $\begin{array}{c}\text { Pulverulento } \\
(\%)\end{array}$ \\
\hline 12,5 & 8,08 & 2,89 & 1,39 & 1,22 & 1,25 \\
\hline
\end{tabular}

Fonte: Elaborado pelos autores.

O diâmetro máximo característico do agregado miúdo é de $12,5 \mathrm{~mm}$, o que caracteriza o material como sendo brita 4,75/12,5 de acordo com a NBR 7211 (ABNT, 2009).

\subsubsection{CARACTERIZAÇÃO DA ÁGUA DE AMASSAMENTO}

Segundo a NBR 15900-1 (ABNT, 2009) a água de abastecimento público é considerada adequada para a produção de concreto e não necessita ser ensaiada.

\subsubsection{CARACTERIZAÇÃO DO PET}

A composição granulométrica do PET foi obtida utilizando como referência a NBR NM 248 (ABNT, 2003). A composição granulométrica pode ser visualizada na Tabela 7, com a curva granulométrica correspondente apresentada na Figura 4. 


\section{Revista Nacional de}

Tabela 7: Composição granulométrica do PET.

\begin{tabular}{cccc}
\hline $\begin{array}{c}\varnothing \text { Peneira } \\
(\mathbf{m m})\end{array}$ & $\begin{array}{c}\text { Massa retida } \\
\mathbf{( g )}\end{array}$ & $\begin{array}{c}\text { \% Retida em } \\
\text { cada peneira }\end{array}$ & $\begin{array}{c}\text { \% Retida } \\
\text { acumulada }\end{array}$ \\
\hline 6,3 & 0,0 & 0,00 & 0,00 \\
4,75 & 0,7 & 0,06 & 0,06 \\
2,36 & 10,7 & 1,05 & 1,11 \\
1,18 & 789,5 & 77,62 & 78,73 \\
0,6 & 176,5 & 17,35 & 96,08 \\
0,3 & 26,5 & 2,61 & 98,68 \\
0,15 & 8,9 & 0,87 & 99,56 \\
0,075 & 4,5 & 0,44 & 100,00 \\
\hline Total & $\mathbf{1 1 9 7 , 3}$ & $\mathbf{1 0 0 , 0 0}$ & $\mathbf{3 7 4 , 2 2}$ \\
\hline
\end{tabular}

Fonte: Elaborado pelos autores.

Figura 4: Curva granulométrica do PET.

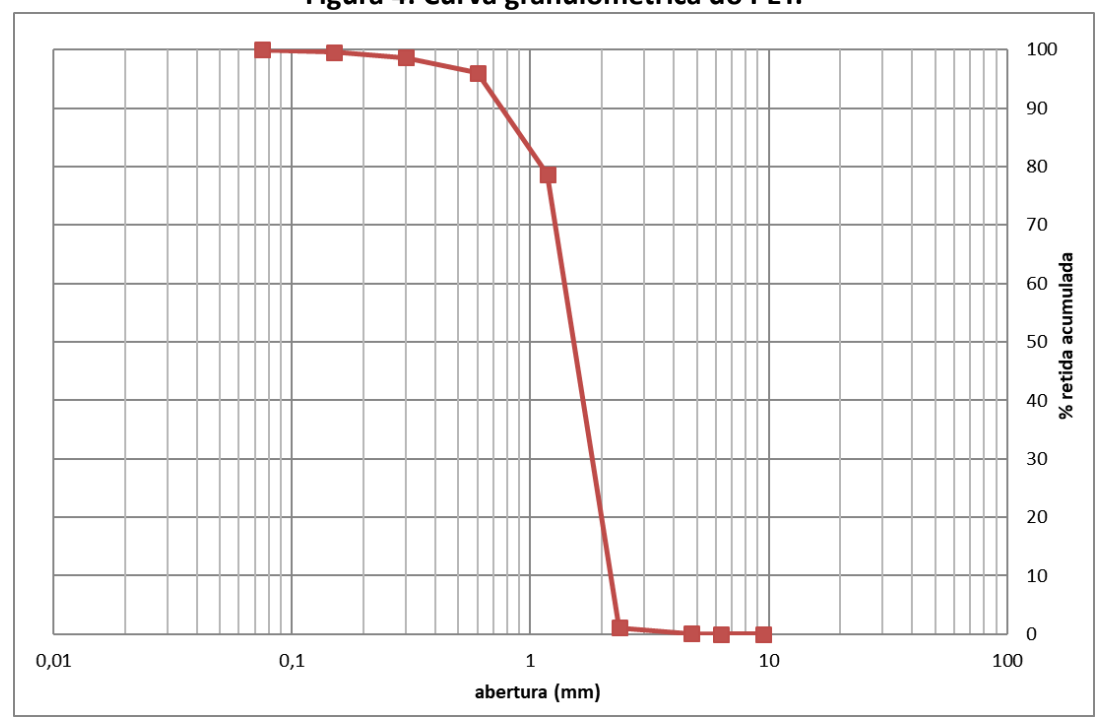

Fonte: Autores, 2018.

Para a determinação da massa unitária do PET seguiram-se as prescrições da NBR NM 52 (ABNT, 2009). Na determinação da massa específica utilizou-se o ensaio conhecido como "Método do Frasco Picnômetro". Os procedimentos adotados neste ensaio serão descritos na sequência:

- pesou-se uma quantidade dos resíduos de pneus em estado natural, denominando a massa "A" (g);

- pesou-se o picnômetro + água denominando a massa " $\mathrm{B}$ " (g), sendo a água colocada até a altura da marca estabelecida no picnômetro;

- retirou-se certa quantidade de água do picnômetro e introduziram-se os resíduos no interior do picnômetro contendo a água; 
- durante 5 minutos retirou-se todo o vazio do conjunto picnômetro + água + resíduos em uma bomba a vácuo, em seguida foi colocado o álcool neste conjunto até a marca estabelecida no picnômetro, pesando em seguida e determinando dessa maneira a massa " $\mathrm{C}$ " (g);

- a Equação 1 foi utilizada para determinar a massa específica $\left(\gamma_{\mathrm{ab}}\right), \mathrm{em} \mathrm{g} / \mathrm{cm}^{3}$ :

$$
\gamma_{a b}=\frac{A}{A+B-C}
$$

Na Tabela 8 são apresentados os índices de caracterização para o PET utilizado.

Tabela 8: Resultados da caracterização do PET.

\begin{tabular}{ccccc}
\hline $\begin{array}{c}\text { Diâmetro } \\
\text { máximo } \\
(\mathrm{mm})\end{array}$ & $\begin{array}{c}\text { Módulo } \\
\text { de } \\
\text { finura }\end{array}$ & $\begin{array}{c}\text { Massa } \\
\text { específica } \\
\text { absoluta } \\
\left(\mathrm{g} / \mathrm{cm}^{3}\right)\end{array}$ & $\begin{array}{c}\text { Massa } \\
\text { unitária } \\
\left(\mathrm{g} / \mathrm{cm}^{3}\right)\end{array}$ & $\begin{array}{c}\text { Absorção } \\
(\%)\end{array}$ \\
\hline 1,18 & 3,74 & 1,35 & 0,43 & 0,10 \\
\hline Fonte: Elaborado pelos autores.
\end{tabular}

\subsubsection{DOSAGEM E PRODUÇÃO DOS TRAÇOS REFERÊNCIA}

O método de dosagem proposto por Helene e Terzian (1992) consiste na dosagem de um traço padrão (1:5), após a definição do teor de argamassa ideal, e na dosagem de um traço rico $(1: 3,5)$ e um traço pobre $(1: 6,5)$, buscando obter os parâmetros ideais para a produção do concreto de forma econômica e coerente com os requisitos de resistência e trabalhabilidade.

O abatimento ideal foi definido como $6 \mathrm{~cm}$ e o teor de argamassa ideal definido foi de $52 \%$, consistindo em um traço padrão de 1:2,12:2,88. O traço rico, para o mesmo teor de argamassa, ficou definido como 1:1,35:2,16 e o traço pobre 1:2,90:3,60.

Utilizando a massa de brita de $10 \mathrm{~kg}$ para todos os traços, por ser suficiente para a realização do ensaio de abatimento de tronco de cone definido pela NBR NM 67 (ABNT, 1998) e para a moldagem de quatro corpos de prova cilíndricos $10 \times 20 \mathrm{~cm}$, o quantitativo dos materiais utilizados ficou conforme mostrado pela Tabela 9.

Tabela 9: Quantitativo de materiais dos traços referência.

\begin{tabular}{cccc}
\hline Materiais & Traço & Traço & Traço \\
$\mathbf{( k g )}$ & $\mathbf{1 : 3 , 5}$ & $\mathbf{1 : 5}$ & $\mathbf{1 : 6 , 5}$ \\
\hline Areia & 6,24 & 7,36 & 8,07 \\
Cimento & 4,64 & 3,47 & 2,78 \\
Água & 2,13 & 1,91 & 1,70 \\
\hline
\end{tabular}

Fonte: Elaborado pelos autores.

\subsubsection{DOSAGEM E PRODUÇÃO DOS TRAÇOS COM PET}

Para a produção do traço com substituição do agregado miúdo por resíduo de PET utilizou-se a mesma metodologia adotada durante a produção do traço de referência, com o mesmo teor 


\section{Revista Nacional de}

de argamassa. No entanto, houve uma ligeira redução na água do traço rico, para manter o slump proposto de $3 \mathrm{~cm}$, adotado em função do uso potencial para a fabricação de peças de pavimentação.

Para a substituição da areia pelo resíduo de PET considerou-se a substituição em volume, uma vez que a massa específica do PET é cerca de $50 \%$ menor do que a massa específica da areia utilizada.

No entanto, utilizou-se a massa de brita de $12 \mathrm{~kg}$, sendo suficiente para a realização do ensaio de abatimento de tronco de cone definido pela NBR NM 67 (ABNT, 1998) e para a moldagem de seis corpos de prova cilíndricos $10 \times 20 \mathrm{~cm}$, o quantitativo dos materiais utilizados ficou conforme mostrado pela Tabela 10.

Tabela 10: Quantitativo de materiais dos traços com PET.

\begin{tabular}{cccc}
\hline $\begin{array}{c}\text { Materiais } \\
(\mathbf{k g})\end{array}$ & Traço & Traço & Traço \\
\hline Areia & $\mathbf{1 : 3 , 5}$ & $\mathbf{1 : 5}$ & $\mathbf{1 : 6 , 5}$ \\
\hline Cimento & 5,24 & 6,18 & 6,78 \\
Água & 5,57 & 4,17 & 3,34 \\
PET & 2,34 & 2,30 & 2,00 \\
\hline
\end{tabular}

Fonte: Elaborado pelos autores.

\subsubsection{SLUMP TEST}

O ensaio de abatimento do tronco de cone, também conhecido por Slump Test, foi realizado segundo as prescrições da NBR NM 67 (ABNT, 1998). Este ensaio é utilizado para avaliar a trabalhabilidade dos concretos produzidos.

O Slump Test foi realizado para todos os traços de concreto para confirmar o abatimento preestabelecido para o cálculo das dosagens.

\subsubsection{RESISTÊNCIA À COMPRESSÃO AXIAL}

Este ensaio foi executado de acordo com as prescrições da NBR 5739 (ABNT, 2007). Foram ensaiados quatro corpos de prova de cada traço de concreto estudado, aos 7 dias de idade.

\section{RESULTADOS}

De posse dos valores de resistência à compressão axial de ambos os traços produzidos é possível compará-los e fazer uma breve análise dos dados obtidos.

Os valores demonstrados na Tabela 11 são referentes ao ensaio de compressão axial dos concretos produzidos para a idade de 7 dias. 


\section{Revista Nacional de}

Apesar da norma brasileira permitir que se adote o maior valor de resistência à compressão do concreto, uma vez que este valor representa a maior resistência potencial do concreto analisado, para uma melhor comparação e análise de resultados, utilizando-se a mesma quantidade de elementos de comparação, desprezou-se o maior e o menor valor obtido das resistências dos traços contendo PET e utilizou-se todo o conjunto de resultados dos traços convencionais.

Tabela 11: Valores de resistência à compressão axial dos traços de concreto produzidos.

\begin{tabular}{ccccccc}
\hline & & $\begin{array}{c}\text { Referência } \\
\text { (MPa) }\end{array}$ & & \multicolumn{3}{c}{$\begin{array}{c}\text { PET } \\
\text { (MPa) }\end{array}$} \\
\hline Corpos de prova & $\mathbf{1 : 3 , 5}$ & $\mathbf{1 : 5 , 0}$ & $\mathbf{1 : 6 , 5}$ & $\mathbf{1 : 3 , 5}$ & $\mathbf{1 : 5 , 0}$ & $\mathbf{1 : 6 , 5}$ \\
\hline 1 & 20,00 & 23,76 & 18,90 & 18,18 & 11,50 & 6,99 \\
2 & 26,96 & 24,23 & 20,99 & 18,70 & 11,83 & 7,23 \\
3 & 30,63 & 26,50 & 22,79 & 21,06 & 12,04 & 7,41 \\
Média & 31,95 & 27,56 & 23,90 & 21,87 & 12,80 & 7,60 \\
\hline
\end{tabular}

Fonte: Elaborado pelos autores.

Também é possível perceber uma queda acentuada na resistência à compressão do concreto com adição de resíduo de PET nos traços 1:6,5 e 1:5,0, se tornando menos significativa no traço 1:3,5, como mostrado na Tabela 12.

Tabela 12: Proporção entre as resistências dos traços produzidos.

\begin{tabular}{cccc}
\hline $\begin{array}{c}\text { Teor de } \\
\text { argamassa }\end{array}$ & $\begin{array}{c}\text { Referência } \\
\text { (MPa) }\end{array}$ & $\begin{array}{c}\text { PET } \\
\text { (MPa) }\end{array}$ & $\begin{array}{c}\text { Proporção } \\
\text { (\%) }\end{array}$ \\
\hline $1: 3,5$ & 27,32 & 19,95 & 73,02 \\
$1: 5,0$ & 25,51 & 12,04 & 47,20 \\
$1: 6,5$ & 21,65 & 7,31 & 33,76 \\
\hline
\end{tabular}

Fonte: Elaborado pelos autores.

Essa relação proporcional entre as resistências é ilustrada na Figura 5. 


\section{Revista Nacional de}

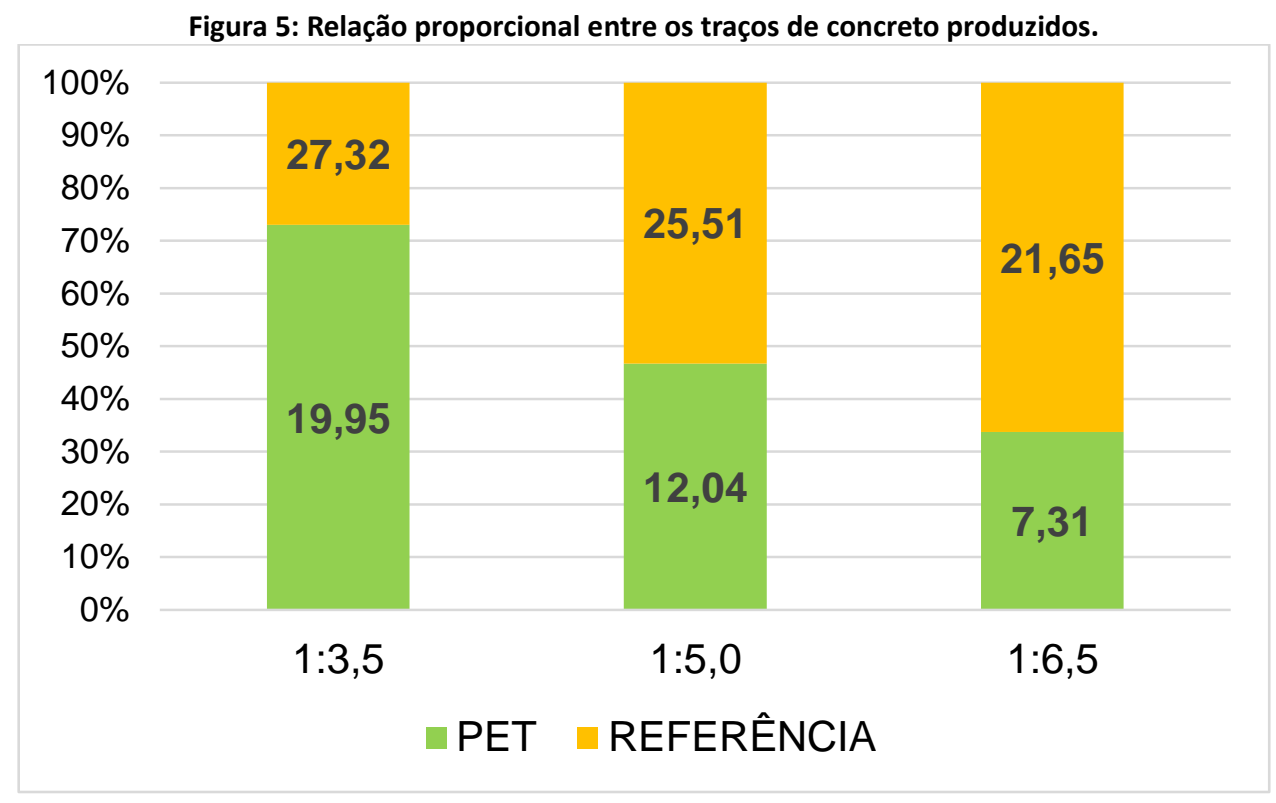

Fonte: Autores, 2018.

\section{CONCLUSÃO}

Com base no que foi apresentado neste trabalho é possível concluir que a substituição de areia pelo resíduo de PET se mostrou mais viável no traço mais rico, oferecendo um caminho a ser investigado dos motivos dessa ocorrência.

$\mathrm{O}$ concreto produzido com resíduo de PET poderia ser usado para fins não estruturais. $\mathrm{O}$ traço 1:3,5 com PET tem uma resistência à compressão esperada, aos 28 dias, de $26,20 \mathrm{MPa}$, o que viabilizaria sua aplicação estrutural. Os demais traços, 1:5,0 e 1:6,5, possuem resistências esperadas em 12,34 MPa e 7,82 MPa, respectivamente. Essa expectativa de resistência foi calculada utilizando o modelo proposto por Helene e Terzian (1992), que relaciona a resistência esperada em função da relação água/cimento e da idade, para o tipo de cimento utilizado, e multiplicando pelo coeficiente proporcional da resistência observado no ensaio aos 7 dias.

Conclui-se, portanto, que a adição de resíduos de PET em concretos deve ser estudada mais profundamente, de forma a viabilizar sua aplicação em peças de responsabilidade estrutural.

\section{AGRADECIMENTO}

Agradecemos ao Laboratório de Engenharia Civil do campus da UNESP de Ilha Solteira pela disponibilidade de espaço e serviços para a realização deste estudo. 


\section{Revista Nacional de}

\section{REFERÊNCIAS BIBLIOGRÁFICAS}

AGOPYAN, Vahan. Construção Civil consome até $75 \%$ da matéria-prima do planeta: Mão de obra e novas tecnologias podem reduzir o consumo de materiais. Globo Ciência, 13 jul. 2013. Disponível em: <http://redeglobo.globo.com/globociencia/noticia/2013/07/construcao-civil-consome-ate-75-da-materia-prima-doplaneta.html>. Acesso em: 24 mai. 2018.

ANEPAC - ASSOCIAÇÃO NACIONAL DAS ENTIDADES DE PRODUTORES DE AGREGADOS PARA CONSTRUÇÃO. 0 Mercado de Agregados no Brasil. São Paulo, 2015.

AGOPYAN, Vahan; JOHN, Vanderley M.. O desafio da sustentabilidade na construção civil. São Paulo: Blucher, 2011.

ASSOCIAÇÃO BRASILEIRA DA INDÚSTRIA DE PET - ABIPET. Décimo censo da reciclagem de PET no Brasil. Publicado em 2016.

ASSOCIAÇÃO BRASILEIRA DE NORMAS TÉCNICAS - ABNT. NBR NM 52: Agregado miúdo - Determinação da massa específica e massa específica aparente. Rio de Janeiro. 2009.

NBR NM 53: Agregado graúdo - Determinação da massa específica, massa específica aparente e absorção de água. Rio de Janeiro. 2009.

NBR NM 67: Concreto - Determinação da consistência pelo abatimento do tronco de cone. Rio de Janeiro. 1998.

NBR NM 248: Agregados - Determinação da composição granulométrica. Rio de Janeiro. 2003.

. NBR 5739: Concreto - Ensaio de compressão de corpos de prova cilíndricos. Rio de Janeiro. 2007.

NBR 7211: Agregados para concreto - Especificação. Rio de Janeiro. 2009.

NBR 7214: Areia normal para ensaio de cimento - Especificação. Rio de Janeiro. 2015.

. NBR 11578: Cimento Portland composto - Especificação. Rio de Janeiro. 1991, versão corrigida 1997.

. NBR 15900-1: Água para amassamento do concreto. Parte 1: Requisitos. Rio de Janeiro. 2009.

VERMA, Rinku et al. Toxic Pollutants from Plastic Waste- A Review. Procedia Environmental Sciences, [s.I.], v. 35, p.701-708, 2016. Elsevier BV. Disponível em: <http://dx.doi.org/10.1016/j.proenv.2016.07.069>. Acesso em 25 mai.2018. 